\title{
FORMATO, PEDAGOGÍAS Y PLANEAMIENTO PARA LA SECUNDARIA EN ARGENTINA: NOTAS SOBRESALIENTES DEL SIGLO XX
}

DOI: http://dx.doi.org/10.1590/2236-3459/82034

\author{
Myriam Southwell' \\ 'Universidad Nacional de La Plata (UNLP), Buenos Aires, Argentina
}

$\cos 8$

\begin{abstract}
Resumen
Este artículo tiene la intención de presentar una panorámica sobre los debates que acompañaron la expansión de la escolarización secundaria en Argentina y las demandas de renovación que se desarrollaron al influjo del movimiento de escuela nueva. Para ello partiremos de un argumento acerca de la existencia de una forma de la escuela media que se consolidó siguiendo determinado modelo, que a partir de allí constituyó una gramática que procesó y modeló las sucesivas intervenciones de reforma y que logró posicionarse como la noción misma de escuela media. Introduciremos los debates sobre reformas necesarias a través de voces sobresalientes sobre los beneficios del escolanovismo en el nivel secundario: Ernesto Nelson, Saúl Taborda y Juan Mantovani.
\end{abstract}

Palabras clave: formato escolar, escuela nueva, espiritualismo.

\section{FORMATO, PEDAGOGIAS E PLANEJAMENTO PARA A SECUNDÁRIA NA ARGENTINA: NOTAS SOBRESALIENTES DO SÉCULO XX}

\section{Resumo}

Este artigo tem a intenção de apresentar uma panorâmica sobre os debates que acompanharam a expansão da escolarização média em Argentina e as demandas de renovação que se desenvolveram ao influxo do movimento de escola nova. Para isso partiremos de um argumento a respeito da existência de uma forma da escola média que se consolidou seguindo determinado modelo, que a partir de ali constituiu uma gramática que processou e modelou as sucessivas intervenções de reforma e que conseguiu se posicionar como a noção mesma de escola média. Introduziremos os debates sobre reformas necessárias através de vozes sobresalientes sobre os benefícios do escolanovismo no nível secundário: Ernesto Nelson, Saúl Taborda e Juan Mantovani.

Palavras-chave: formato escolar, escola nova, espiritualismo.

\section{FORMAT, PEDAGOGIES AND PLANNING FOR HIGH SCHOOL IN ARGENTINA: HIGHLIGHTS OF THE 20TH CENTURY}

\begin{abstract}
This article intends to review the ways in which secondary schooling was expanded in Argentina and the debates and demands for renewal that developed at the influence of the new school movement. Our starting point is an argument about the existence of a form of the secondary school that consolidated following determinate model, that from there constituted a grammar that processed successive interventions of reform
\end{abstract}


and that attained to position like the very notion of secondary school. We will introduce debates on necessary reforms throughout standing voices promoted of new school movement: Ernesto Nelson, Saúl Taborda and Juan Mantovani.

Keywords: school format, new school, spiritualism.

\section{FORMAT, PEDAGOGIES ET PLANIFICATION POUR LE LYCEE EN ARGENTINE: FAITS SAILLANTS DU 20EME SIECLE}

\section{Résumé}

Cetarticle vise à examiner les manièresdontl'enseignementsecondaires'estdéveloppé en Argentine et les débats et demandes de renouveauqui se sontdéveloppés à l'arrivée du nouveaumouvementscolaire. Pour cela, nouscommençons par un argument sur l'existenced'une forme d'écolemoyenneconsolidéesuivant un certainmodèle, qui de làétait une grammairequitraitait et modélisait les interventions de réformesuccessives et réussissait à se positionnercomme la notionmême de collège. Nousprésenterons les débats sur les réformesnécessaires à travers des voixexceptionnelles sur les avantages de la scolastiqueauniveausecondaire: Ernesto Nelson, Saúl Taborda et Juan Mantovani.

Mots-clés: format de l'école, nouvelleécole, spiritualisme. 
$R$

epasar la historia del nivel secundario proporciona algunos elementos estructurantes de la organización escolar y sus mitos fundantes de gran perdurabilidad. Este artículo tiene la intención de reseñar los modos en los que se fue expandiendo la escolarización secundaria en Argentina y los debates y demandas de renovación que se desarrollaron al influjo del movimiento de escuela nueva. Para ello partiré de la base de un argumento que desarrollé en otros trabajos (SOUTHWELL, 2009, 2011, 2012) acerca de la existencia de una forma de la escuela media que se consolidó siguiendo determinado modelo e incluyendo rasgos específicos, que esa construcción se consolidó como un formato ${ }^{1}$, que a partir de allí constituyó una gramática (TYACK; CUBAN, 2000) que procesó y modeló las sucesivas intervenciones de reforman y que logró posicionarse como la noción misma de escuela media. Introduciremos los debates sobre reformas necesarias a través de las voces más sobresalientes sobre los beneficios del escolanovismo en el nivel secundario: Ernesto Nelson, Saúl Taborda y Juan Mantovani.

El planteamiento del que partimos sitúa a las prácticas socializadoras dentro de la escuela en perspectiva socio-histórica, permite analizar la hegemonía de la forma escolar y formular la hipótesis de que las transformaciones de la institución escolar y de las relaciones de los diferentes grupos sociales participan de la reactualización de esa forma hegemónica. Esa perspectiva permite dar cuenta de que las reformas institucionales y pedagógicas se suceden, contribuyendo a transformar los contornos de la escuela, la manera en que es percibida y las prácticas de los diferentes grupos sociales.

\section{Escuela secundaria, modernización y educación de las elites}

La escuela secundaria argentina tiene un punto de origen muy significativo en torno a 1860, con la puesta en funcionamiento de Colegios para la formación de las élites que llevaba un modelo unificado de educación liberal a todas las grandes ciudades del país. La función política de los Colegios Nacionales se orientaba hacia la transformación de los sujetos sociales heterogéneos en sujetos políticos homogéneos, a través de la incorporación a un sistema político institucional restringido. Abarcaron a un porcentaje muy bajo de la población, reclutaban su matrícula en los sectores más acomodados, varones, para continuar estudios universitarios y formar a los administradores del Estado que se estaba conformando.

En su expansión - desde 1863 a 1916 - hubo 17 curricula diferentes (es decir, un cambio de plan cada tres años, que además no se aplicaban gradualmente, lo que dio paso a planes superpuestos), variando la cantidad de asignaturas. Las humanidades se volvieron un signo de distinción cultural, pero también una tecnología del yo, en términos de que implicaron un trabajo de gobierno de las pasiones e inclinaciones del individuo; ser capaz de especular y contemplar la naturaleza, o las "altas obras de arte" era parte de una

\footnotetext{
${ }^{1}$ En este análisis, será significativa la conceptualización desarrollada por Vincent, Lahire y Thin (1994) acerca de la forma. Bajo el nombre de forma escolar remiten a una configuración socio-histórica, surgida en las sociedades europeas entre los siglos XVI-XVII, que da como resultado un modo de socialización escolar que se impuso a otros modos de socialización. Hablar de forma escolar es por lo tanto investigar sobre aquello que confiere unidad a una configuración histórica particular, surgida en determinadas formaciones sociales y que se constituye y tiende a imponerse, retomando y modificando ciertos elementos de formas antiguas. Los diversos aspectos de esta forma deben analizarse como unidad, de otro modo solamente podría ser una enumeración de múltiples características. A lo que estamos haciendo referencia es a una forma inédita de relación social que se denomina pedagógica; inédita en el sentido en que es distinta y se autonomiza en referencia a otras relaciones sociales.
} 
transformación más general en las formas en las que los individuos debían ser gobernados, y gobernarse a sí mismos. (DUSSEL, 1997). Se trataba de una formación que preparara "para todo", sin especialización, implicaba cinco años de cursado y se organizaba en ramos de la enseñanza. Los distintos curricula en esas décadas incluían el continuum lengualiteratura nacionales, disciplinas científicas e historia y geografía con un peso creciente (DUSSEL, 1997). En las sucesivas modificaciones se fue articulando la enseñanza clásica que se conocía a través de la experiencia europea con la formación de una identidad nacional. Por ejemplo, el lugar de las lenguas clásicas fue ocupado por las modernas: "la inserción en el mundo era tanto o más importante para la elite de los colegios nacionales que el dominio de la lengua propia". (DUSSEL, 1997, p. 27).

El enciclopedismo se convirtió en el ideal formativo de los colegios nacionales y se convirtió en la única acepción posible para el enunciado "enseñanza general". La hipótesis de Inés Dussel para el período que ella estudia - 1863-1920 - es que los intentos de reforma más profundos fueron rechazados porque intervenían entre esta equivalencia de "enseñanza general" y "curriculum humanista". Asimismo, entre las razones de esta perdurabilidad se encontraba el modo en que ese patrón cultural, mezclaba la herencia del viejo humanismo con las humanidades modernas, lo que lo transformó en un signo de distinción cultural, un valor más alto para ciertos sectores que la orientación hacia una preparación laboral. Este patrón cultural fue efectivo porqué logró articular las expectativas y estrategias político-culturales de diversos grupos. De este modo, el curriculum enciclopédico se convirtió en la forma hegemónica de la escuela media, una instancia preparatoria basada en la distinción y el carácter elitista de la "alta cultura". (DUSSEL, 1997).

Dentro de la selección curricular los saberes del trabajo y las ocupaciones manuales quedaron al margen de lo que se consagró como la enseñanza deseable y valiosa para la escolaridad secundaria. Esta característica estuvo entre aquellos aspectos que se propusieron modificar en diversas ocasiones. Los saberes del trabajo continuaron golpeando "a la puerta" del curriculum sistemáticamente y su inclusión fue problemática, ubicados primero en circuitos subvalorados que tuvieron que trabajar mucho para ir logrando un reconocimiento mayor. El curriculum de las Escuelas Normales era muy estable, con su característica de enciclopedismo (TEDESCO, 1986; PUIGGRÓS, 1990), con su concepción positivista y orientado a la formación en la práctica de la enseñanza.

Con algunas modificaciones generadas entre fines del siglo XIX y comienzo del XX, la rígida separación entre Colegios Nacionales y Escuelas Normales se hacía más porosa, aunque seguirían reclutando a distintos sectores sociales y con distinta finalidad. La modernización curricular garantizó una perdurabilidad mucho mayor de la formación de los Colegios Nacionales que el viejo currículum humanista clásico, aunque no anuló las impugnaciones formuladas referidas a la formación que no proveía.

La primera década del siglo XX muestra ya un formato con determinados rasgos estables que hemos venido mencionando: el saber escolar separado en gajos o ramos de la enseñanza (asignaturas o materias), la enseñanza simultánea de esas asignaturas, formación de docentes en relación con esa división de gajos o materias de la enseñanza, un curriculum graduado - es decir - una determinada secuencia con la aprobación de las materias en simultáneo y encadenadas propedéuticamente (promocionando de un año a otro sólo a través de la aprobación de todas la asignaturas), una secuencia fija, con 
agrupamientos escolares en base a la edad, el aula/sección como unidad espacial, el ciclado y el año escolar como unidades temporales, un curriculum generalista y enciclopédico, una jerarquía de saberes vinculado a formas de distinción social, una fuerte presencia de la lógica meritocrática, dispositivos de evaluación - el examen, con una dimensión privada del sujeto y una pública representada en las acreditaciones, el individuo como unidad de formación, el distanciamiento de la vida "mundana" o de la vida por fuera de la escuela, la condición de preparatorio para lo que vendría después. A ello se agregaba la neutralidad y la objetividad como pilares (DUSSEL, 1997) de su función social. Pedagogía, política, administración y moral se articularon y dieron por resultado un "sentido común" sobre la enseñanza. Así se constituyó una suerte de matriz que persistió con ligeras modificaciones a lo largo de todo el siglo XX e incluyó la existencia de algunas instituciones educativas como modelos de referencia para el conjunto de las instituciones del nivel.

Nos interesa situar los debates que se producen en la primera mitad del siglo XX a través de las perspectivas, críticas y proyectos de reforma impulsados por tres educadores muy destacados que ocuparon puestos de gestión en el nivel secundario, como directores de Colegios, inspectores y autoridades ministeriales. Ellos son Ernesto Nelson, Saul Taborda y Juan Mantovani. Ellos compartieron una serie de elementos centrales en la comprensión de estos debates: la influencia que sobre ellos tuvo el movimiento de la escuela nueva, su adscripción al espiritualismo en sus diversas expresiones, la demanda por la modificación del formato del Bachillerato clásico y el impacto que en sus concepciones tuvo el clima cultural gestado con el movimiento de Reforma Universitaria que se desplegó a partir de 1918 (la participación de Taborda y Mantovani en el movimiento reformista fue muy importante). Respecto a ese clima de renovación desde la universidad, es preciso hacer una puntualización. Los tres educadores transitaron las instituciones de la Universidad Nacional de La Plata en las décadas del '10 y el '20 (Nelson como director del Internado del Colegio Nacional, Taborda como estudiante de Derecho y posteriormente como director del Colegio Nacional, Mantovani como estudiante de Pedagogía y catedrático). En esa universidad, el discurso reformista tomó características peculiares, debido a que algunas de las demandas del movimiento reformista ya formaban parte del modelo universitario - el modelo Humboldtiano - con el que había sido creada la de La Plata; la vinculación con la comunidad a través de la extensión universitaria, la renovación y los concursos para la provisión de docentes, ya eran parte de su funcionamiento. Sin embargo, un aspecto propiciado por el clima de revisión universitaria y que tuvo especial condensación en el escenario platense fue la oposición al positivismo - concepción científica predominante en la Universidad de La Plata y en particular en sus estudios pedagógicos ${ }^{2}$ y el carácter elitista de los colegios nacionales universitarios. ${ }^{3}$

\footnotetext{
2 En 1906 se crea la Sección Pedagógica y a partir de ella, la Facultad de Ciencias de la Educación en 1914, ambas instancias en la Universidad de La Plata.

${ }^{3}$ Las instituciones de nivel medio en Argentina hasta ese momento eran: los colegios nacionales creados a partir de 1863 y las escuelas normales fundadas a partir de 1870, como dos circuitos completamente separados. También en el inicio del siglo XX se crearon las primeras escuelas industriales y comerciales. En 1905, se resolvió que sólo algunos de los colegios nacionales se convirtieran en colegios universitarios, con dependencia de las universidades existentes: Córdoba, Buenos Aires, La Plata y Tucumán. Los demás continuaron siendo colegios nacionales, sin dependencia de una Universidad.
} 


\title{
Tradición y expansión: el despliegue del formato
}

Ernesto Nelson (1873-1959) fue director del Internado del Colegio Nacional de La Plata e Inspector de Enseñanza Media en las primeras dos décadas del siglo XX. Con él, el escolanovismo, pero en particular las ideas de John Dewey ${ }^{4}$, encontraron una expresión en el curriculum de la escuela media: introdujo el fútbol, el cine, la prensa y los viajes de estudio como formas educativas tan o mas valiosas como las disciplinas escolares. Así lo expresaba: "La cultura es un resultado natural del ejercicio de la curiosidad y del interés, siendo realmente milagroso el que no haya sucumbido a consecuencia de los refinamientos de una mal llamada educación, que parece empeñada en hacer odioso todo aprendizaje". (NELSON, 1919, p. 518).

Nelson cuestionaba ya en 1915 el plan de estudios rígido y una secuencia de reformas que no habían modificado esa característica. Le propuso al Ministro de área un Plan de Reformas para la Enseñanza Secundaria. Buscaba modificar el curriculum mosaico y su componente interno de simultaneidad abriendo la posibilidad a trayectorias y ritmos de aprendizaje diversos; planteaba un agrupamiento de asignaturas dependiendo de departamentos de áreas, posibilitando que el alumno pueda desarrollar recorridos distintos. Buscaba con ello evitar que "un alumno reprobado en álgebra no pueda cursar historia moderna". Ofrecía una muy interesante analogía con una Biblioteca Pública:

\begin{abstract}
Obsérvese que sería irritante y absurdo el que una biblioteca escatimase los libros a quienes acudiesen en demanda de lectura; que obligase a leer por estantes completos, en los que se hubieran agrupado libros de asuntos inconexos, no permitiendo el paso de uno a otro estante al que no hubiera terminado el precedente; que expulsara de su recinto a los que fracasaran en la tentativa de leer lo que no agradara o no encontrara eco en la disposición natural del lector [...] Pues esto, exactamente, es lo que ha venido haciendo el colegio. (NELSON, Plan de Reformas a la Enseñanza Secundaria, p. 93).
\end{abstract}

Su plan nunca se implementó. La expansión del nivel incluyó la creación de ramas o modalidades diferentes para los sectores sociales que no accederían a los estudios superiores. Sin embargo -tal como han mostrado los estudios de Gallart (1984a, 1984b, 2006) las nuevas modalidades tuvieron una escasa incidencia frente a la valoración del título de "bachiller" para los sectores dominantes y para las clases medias en ascenso en la Argentina de las primeras décadas del siglo $X X^{5}$ su impronta generalista, humanista y enciclopédica logró hegemonizar la noción misma de escuela secundaria legítima. Ese peso, además, resultaba deslegitimador para las demás modalidades a las que se buscó jerarquizar en distintos momentos, emparentándolas con el plan general del Bachillerato.

En 1916 el ministro Saavedra Lamas impulsó una reforma cuya idea central fue

\footnotetext{
${ }^{4}$ Ernesto Nelson fue un educador que se desempeñó en la escuela secundaria, de la que fue inspector y produjo un Plan de Reformas para ese nivel de la enseñanza, entregado al Ministerio de Educación. que produjo una serie de intervenciones públicas sobre distintos aspectos que eran parte de la agenda pública prioritarios del comienzo del siglo XX: la delincuencia juvenil, la civiización argentina, las bibliotecas populares, la formación de la juventud. Entre 1902 y 1906 estudió en Columbia, donde conoció a John Dewey en Teachers College. Se ocupó de traducir e introducir parte de la obra de Dewey en América del Sur. También fue un enfático promotor de la cultura norteamericana y como parte de ese impulso fue uno de los fundadores del Instituto de Cultural Argentino Norteamericano (Icana) y del Rotary Club.

${ }^{5}$ La escuela técnica, por ejemplo debió recorrer mucho trayecto para sobreponerse a su estigma de modalidad de menor valor. Por otro lado, las modalidades bachillerato, comercial y técnica remitían a saberes y sectores sociales diferenciados y también la presencia de "colegio del centro" hablaba de jerarquías y lugares claramente definidos.
} 
transformar los cuatro tipos de escuelas secundarias paralelas (Colegio Nacional o Bachillerato, Normal, Comercial e Industrial), generando una Escuela Intermedia común, de cuatro años, a continuación de sólo cuatro de enseñanza elemental; esta Escuela Intermedia debía preparar para una salida laboral. El tramo final, el secundario superior debía preparar para actividades diferenciadas: una rama académica preparatoria para la universidad especializada en diversos campos científicos y humanísticos y otras tres especialidades (Normal, Comercial e Industrial) más vinculadas a inserciones laborales. ${ }^{6}$ Esta nueva organización se implementó sólo por algunos meses y luego fue suspendida y retrotraída a la organización anterior.

Durante la década del '20 surgieron dos nuevos proyectos de reforma que no se concretaron. El primero buscaba reducir la cantidad de años de la escuela y encomendaba los cursos preparatorios a la propia Universidad. El segundo - en 1923 - tenía algunas características del plan Saavedra Lamas en su diferenciación entre educación preparatoria y vocacional, pero mantenía el peso en la educación general durante los primeros años de la secundaria y no innovaba en la articulación con la primaria. Aquel canon pensado y diseñado mucho tiempo atrás - como proyecto institucional y como cultura política - logró sistematizar y moldear un formato como referencia inevitable a la que tendía en su expansión. La dinámica logró encontrar un cauce para masificarse pero a la vez mantener uniformidad respecto a funciones, formas de institucionalización y funciones sociales y políticas. En términos curriculares, los cambios fueron énfasis en contenidos nacionalistas, mayor o menor enseñanza de lenguas extranjeras y otras modificaciones similares.

Nelson, Taborda y Mantovani reaccionaron contra lo que entendían como una profundización utilitarista, el énfasis en la orientación práctica. Juan Mantovani (18981961) ${ }^{7}$ estudio Pedagogía en La Plata. Alí y en la Escuela Normal Mariano Acosta entró en profunda relación con el escolanovismo, que estuvo significativamente activo en los cargos de conducción educacional que desempeñó hasta la década de 1940. Impulsó una estrategia de reforma en la década del '30, que propuso una organización distinta a través de ciclos, que incluían la formaciones específicas mientras fortalecía estrategias de unificación:

A la enseñanza secundaria que se imparte en los colegios nacionales y liceos, le
atañe una función profundamente unificadora, desde que sirve con acentuado
predominio a dos conceptos esenciales para la vida de nuestro pueblo y de cada
individuo: la nacionalidad y la cultura. De ahí la uniformidad de sus planes. Las
escuelas técnicas necesitan, en cambio, planes diversos, de acuerdo con sus fines
diferenciados. Pero esto mismo les impone, por otro lado, una tarea de unificación,
que difiere de intensidad según se trate de escuelas técnicas elementales o medias,
y esto se logra por los conocimientos generales, que son los que aclaran, en gran
medida, las cuestiones especializadas. Solamente por el órgano de una cultura

${ }^{6}$ La reforma Saavedra Lamas significó una intervención significativa en la modificación de la escuela media desde el punto de vista de la duración de la escolaridad su organización y también sus aspectos curriculares. Como han analizado Tedesco y Puiggrós, esta reforma debía tener un efecto "desescolarizador" para los sectores populares, que según esperaban sus autores, sería desviado al sistema productivo antes de llegar a la educación secundaria. ${ }^{6}$ Por eso fue derogada en 1917, como una de las primeras medidas del gobierno de Hipólito Yrigoyen, y se retornó al status quo que era el bachillerato clásico de formación general.

7 Juan Mantovani fue un educador normalista, que se formó en los años de mayor impulso de la Reforma Universitaria fue asimismo protagonista de la difusión del escolanovismo como movimiento de gran renovación del sistema educativo del siglo XIX. En su vida profesional, compartió su tiempo de trabajo como profesor universitario, con una importante tarea como funcionario educativo, que impulsó una importante reforma educacional. 
suficiente que facilite la realización del trabajo común o la iniciativa y creación en el esfuerzo original - variable según la realice un obrero, un arte - sano o perito director -, adquieren fertilidad la técnica y la profesión. Lo opuesto es mero automatismo, es pura mecanización. Sin algo creador no hay en el trabajo ni emoción ni continuidad, es decir, rastro esencialmente humano. (MANTOVANI, 1937, p. 17-18).

Desde sus puestos de gestión gubernamental buscó soluciones en relación con la expansión creciente de la matrícula y las reformulaciones internas que demandaban a la propuesta curricular. Cuando se desempeñaba como Inspector General de Enseñanza Secundaria, Normal y Especial, Mantovani publicó el Proyecto de reformas a los planes de estudio de la enseñanza media (1934) que se basaba en un aumento de los años de estudios en la enseñanza media, desarrollar una estrecha vinculación entre las distintas direcciones de la enseñanza media, con propósito de unificación cultural, apoyar los estudios de la enseñanza media sobre una estructura general, sobre la base de dos ciclos: uno inferior, común, cultural y otro, superior, de intensificación cultural en el bachillerato y de especialización técnico-profesional en las demás direcciones (normal, comercial e industrial). También, el fomento de los "estudios relativos al conocimiento del país y de orientar dentro de un espíritu acentuadamente nacionalista la educación de la juventud". (MANTOVANI, 1934, p. 4).

\section{Espiritualismo, escuela nueva y bachillerato}

Desde los inicios del siglo XX, el sistema educativo argentino atendió, con operaciones pedagógicas propias, las tensiones que los procesos de modernización cultural y social introducían en la vida cotidiana, proponiendo patrones de selección y valoración de nuevas subjetividades. El clima social de la post-guerra ponía en crisis los preceptos más racionalistas que había instalado el liberalismo decimonónico. En palabras de Funes "La Primera Guerra Mundial limó todas las mayúsculas decimonónicas: Razón, Civilización, Progreso, Ciencia" (FUNES, 2006, p. 13). Asimismo, lo inconcluso de algunas promesas del desarrollo educativo del siglo XIX, contribuyeron a la erosión del sujeto liberal.

Ese contexto discursivo generó las condiciones de posibilidad para el despliegue de alternativas y concepciones renovadoras en el marco de las insuficiencias que mostraban las instituciones generadas en el siglo anterior. Ello configuró un marco importante para el surgimiento de espiritualismos de diverso tipo y una vinculación mayor de conocimiento con sus razones social y contextual. El apoyo en la ciencia positivista y en las explicaciones y recomendaciones que habían generado la biología y la higiene como paradigmas conceptuales, estaba en declive. Contrariamente, se propiciaba la inclusión de otras fuentes y formas de conocimiento ligadas a la sensibilidad (la intuición, la percepción) como nuevas herramientas de intelección y de producción. Por otro lado, de la mano de la producción conceptual pedagógica y psicológica, la presencia de los intereses del niño y su posición activa en el aprendizaje produjo la primera gran crítica a la pedagogía normalista que desarrolló el movimiento de Escuela Nueva.

Este conjunto de elementos tuvieron especial presencia en la renovación pedagógica de esos años, impulsando nuevos ideales de ciudadanía, moralidad y renovación estéticas, formas sensibles de representación del mundo que pugnaban por volverse hegemónicos en el período. 
Saúl Taborda (1885-1944) ${ }^{8}$ fue designado rector del Colegio Nacional de la Universidad de La Plata en 1921. Entre 1923 y 1927, estudió en Marburgo (Alemania) con Paul Natorp, luego en Zurich, Viena y París. A su regreso a la Argentina fue designado en 1942 como Director del Instituto Pedagógico de la Escuela Normal Superior de Córdoba. Desde su temprana obra, Taborda reflexiona sobre los sistemas sociales, las formas estaduales, las instituciones políticas y educativas de la civilización europea, a la que la declara "inepta para realizar las nuevas concepciones del espíritu". Tradujo a Carl Smichtt, para comprender cómo se emancipaba no sólo el campo intelectual nacional, sino para proyectar transformaciones en el Estado, la Nación y la democracia.

Taborda criticó fuertemente al positivismo, presente en las universidades latinoamericanas el modelo experimental de las universidades norteamericanas pensadas en torno a actividades vinculadas a facultades, en las que se estudiaba predominantemente con fines prácticos. Sus criticas estaban dirigidas a las doctrinas darwinianas vinculadas a las formas de la enseñanza y a los contenidos pedagógicos y aquello que calificaba como el sello positivista en el trabajo de los educadores que los convertía en administradores de la educación.

Una referencia central para entender la crítica social sostenida por Taborda es el movimiento intelectual, político y pedagógico de la Reforma Universitaria de 1918 y se extiende - a través de la expansión del espiritualismo y el movimiento escolanovista - hasta mediados de la década del ' 40 desplegando el ideario reformista en el sistema educativo en su conjunto. Las referencias a la Nación, el federalismo, la espiritualidad (en términos filosóficos y laicistas) y un fomento de la participación estudiantil, desafiaron y renovaron su discurso pedagógico, articulándolo profundamente con lo político y el reformismo social.

El período histórico que se abre luego de la finalización de la Primera Guerra Mundial, inaugura una etapa de revisión y renovación vinculadas fundamentalmente a la idea de crisis, de modernización, el rol de los intelectuales y la política, la Nación, el antimperialismo, los proyectos políticos de transformación social, la interpelación/representación de los grupos subalternos, en términos de clase, étnicos y/o etarios (obreros, campesinos, jóvenes), la idea de cultura como portadora de valores emancipatorios. Probablemente no se había puesto de manifiesto de forma tan evidente la "juventud de América Latina" hasta que la "vieja" Europa sintió el agotamiento de la Primera Gran Guerra. (FUNES, 2006). En ese contexto se desarrollaron complejas relaciones entre Nación, crisis y modernidad en una década en la que se despliegan formas contrahegemónicas de poder y surgen formas de pensar críticas y alternativas al orden instituido, a los cánones y las genealogías desarrolladas con anterioridad. Las nociones de modernización y de Nación fueron reocupadas con otros componentes: vitalismo, espiritualismo, intuición, misticismo, sensibilidad, estética.

La crisis desarrollada a partir de la Gran Guerra, la relativización de Europa como

\footnotetext{
8 Saul Taborda estudió en la Escuela Normal de Córdoba y luego en el Colegio Nacional de Rosario. En 1908 se trasladó a La Plata, donde se graduó de abogado y en 1913 se doctoró en Derecho y Ciencias Sociales en la Universidad del Litoral. En esa Universidad se desempeñó como profesor de Sociología y en 1921 fue designado rector del Colegio Nacional de La Plata. Simultáneamente, era Consejero de la Facultad de Derecho y Ciencias Sociales de Córdoba; allí impulsó la creación del Seminario de Filosofía y Humanidades, simiente de la actual Facultad de Filosofía y Humanidades. Dos años más tarde, partió a Europa, donde permaneció hasta 1927, estudió en Marburgo (Alemania) con Paul Natorp, luego en Zurich, Viena y París. A su regreso a la Argentina se dedicó a la docencia, aunque fuera de la Universidad y en 1942 fue designado Director del Instituto Pedagógico de la Escuela Normal Superior de la provincia de Córdoba.
} 
faro de la cultura y la creciente oposición a las agresivas políticas militares de Estados Unidos sobre la región fueron generando dudas, rumbos significativos y un novel continente de sentidos en el mundo de las representaciones. La etapa estuvo marcada por la puesta en crisis de algunas convicciones decimonónicas, la crisis económica, la pluralización de formas y expresiones culturales, la apertura de otras fuentes de conocimiento tales como la sensibilidad (atendiendo a la influencia bergsoniana). Ante las insuficiencias mostradas por el modelo racionalista, se presentó un escenario particular para la enseñanza. Como destaca Funes (2006) para los años '20 la revolución, el socialismo, el comunismo, el antiimperialismo, el corporativismo, la democracia y la modernidad fueron tópicos que recorrieron la reflexión de los actores que se ubicaron desde el campo de la cultura y la sociedad. Pero, especialmente, recayó sobre ellos la tarea de pensar y crear interpretaciones y lecturas en torno a la Nación, entidad de sentido conformada desde múltiples y ambivalentes significados al calor de una discusión que atravesaba tanto el plano filosófico-cultural como el político. La apertura de nuevos horizontes y metáforas de la época permitió romper con aquellas visiones endógenas y cerradamente nacionalistas que configuraron los imaginarios y resortes sobre los que reposaban las historiografías nacionales y abrir canales de diálogo entre distintas tradiciones. En la perspectiva tabordiana, Europa había fracasado; ya no podía guiar al mundo y eso hacía que comenzara la hora de América con las enseñanzas que extraía de la historia ya que conocía el proceso evolutivo y las causas de la derrota europea.

Las críticas de Taborda también tuvieron como destinatarios el deterioro del Estado y - en general - el modelo institucional. Buscaba reemplazar la idea de imperium que se había consolidado bajo el concepto de soberanía estadual cerrada y que desembocaba en el hecho de que cada Estado se transformara en una idea insolidaria, irresponsable y extraña a las sanciones del derecho internacional. ${ }^{9}$ Con un nacionalismo que en Taborda coincidía con la crítica al positivismo y que se desarrollaría en pro de un latinoamericanismo con elementos de neo-idealismo, ya a fines de los años 30 y comienzos de los 40 ese nacionalismo tomará la forma de comunalismo. A partir de ese diagnóstico, propone un retorno a lo ecuménico a través de su idea de comunalismo y discute, con ello, la presunción del carácter conservador de la tradición, ya que en su pensamiento ocupa un lugar vivificador y de renovación moral. Esta es la fuente del comunalismo, un orden existencial que entrañaba a lo popular, generado por las tradiciones de cada espacio territorial.

Con preocupaciones similares, Mantovani se ocupaba de la articulación entre lo local y lo universal, buscaba un nuevo humanismo occidental que partía de la base de reconocer una ausencia: la de un "macrocosmos" de valores con alcance universal, "un sello nacional, pero con un poder de comunicación universal”.

Lo que da coherencia a la propuesta pedagógica de Mantovani es el peso puesto en una homogeneidad potencial presupuesta en el pueblo, que se transforma en una colectividad homogénea a través de la mediación institucional del sistema escolar. (BENTIVEGNA, 2011, p. 158).

\footnotetext{
9 "El Estado como instrumento de la clase capitalista es inconciliable con una sociedad de naciones y el conflicto chino japonés, debajo del cual se debate un afán febril de expansión económica, es la prueba más palpitante de la inocuidad del remedio escogido para superar la crisis del Estado". Saúl E. Taborda: La Crisis Espiritual y el Ideario Argentino" Conferencia pronunciada bajo los auspicios del Instituto Social. Publicado por el Instituto Social de la Universidad Nacional del Litoral. Santa Fe. R. Argentina, 1933.
} 
En consonancia con los planteos de Nelson en la primera década del siglo, Mantovani planteaba que

El hombre real es aquel que supera la mera individualidad biológica y trasciende hasta la comunidad cultural. La educación, en su elevado sentido de formación, es la realización del individuo en la comunidad cultural. Es la formación del individuo socializado, y vinculado a los valores objetivos de la cultura. En una palabra, la formación de la persona. (MANTOVANI, 1933, p. 228-229).

En los tres educadores está la preocupación de dotar de espiritualidad a procesos formativos que veían excesivamente centrados en aspectos utilitarios:

Será mejor maestro quien sea más universalmente hombre. Y es tal quien es más culto, no más especializado. Más cultura y menos técnica será mayor estímulo a las fuerzas creadoras que a la mera imitación. La cultura eleva hasta la universalidad. La técnica mantiene el espíritu en la especialidade. (MANTOVANI, 1930a, p. 156).

Ernesto Nelson estuvo a cargo de una de las comisiones que organizó Mantovani para su plan de reformas y allí planteaba la necesidad de:

formar espiritualmente al adolescente, esto es, organizar en él la capacidad para observar, comprender y valorar tanto los fenómenos del no-yo como los del yo"; $\left(2^{\circ}\right)$ "despertar y fortalecer en los alumnos los que podrían llamarse valores de convivencia, es decir, todo aquello relacionado con los deberes de cooperación y nuestra consideración impuestos por la vida en sociedad, y cuyo descuido es una de las deficiencias que más urge corregir [...; $\left(3^{\circ}\right)$ impartir una suma de conocimientos que sea, a la vez, contenido de cultura general y preparación para los estudios superiores y $\left(4^{\circ}\right)$ proveer al adolescente de algunos instrumentos útiles cuya naturaleza sea tal que haga más completa la preparación de los estudiantes que puedan terminar sus estudios secundarios y coloque en condiciones más ventajosa que las actuales (para incorporarse a otras actividades) a aquellos que por cualquier circunstancia se alejen de esos estudios antes de concluirlos (NELSON, Plan de Reforma de 1934, p. 26-27, itálicas en el original).

Formar hombres totales, completos, de vida plena. ¿Cómo hacerlo con la enseñanza media? Pues estableciendo asignaturas-eje que tiendan a la formación de hombres así. El estudio a fondo del castellano - que vinculará al adolescente, que proviene en gran parte de hogares extranjeros, con la tradición hispánica del país y lo dotará del instrumento de relación imprescindible -, de la historia - que lo ubicará en el punto y momento justo en que ha nacido y le hará ver el camino de sus esfuerzos posibles - y de un idioma extranjero - que lo pondrá en contacto con una cultura de gran magnitud - es, seguramente, el que lo logrará mejor. Las demás asignaturas girarán en torno de este eje, y contribuirán, en menor o mayor medida, a formar hombres cultos. (MANTOVANI, 1934, p. 125-126, itálicas en el original).

Su apuesta a la formación integral y la espiritualidad, no dejaba de ser laicista y humanizante. Nelson y sobre todo Taborda y Mantovani sostuvieron posiciones anticlericales, de solidaridad social, articuladas con un vivo americanismo, antimilitarismo y antiimperialismo. El humanismo que impulsaban aspiraba a la integralidad de los valores, por lo cual incluye los valores religiosos, pero orientados en una neutralidad vinculada al laicismo entendido como forma de libertad.

\section{Entre la docencia emancipadora y las limitaciones de la institucionalización}

Durante las primeras cuatro décadas, las intervenciones de los educadores 
referenciados - aún con matices - marcaban la necesidad de renovación de la división disciplinar del conocimiento, de las metodologías de enseñanza y de la perspectiva adultocéntrica, que había sido producto de las concepciones enciclopédicas y positivistas. Un aspecto que prevalecía era la renovación pedagógica entendida como el modo de combatir la artificiosidad de la pedagogía normalista. El naturalismo dio, al menos inicialmente, gran valor a los principios de espontaneidad y libertad natural como principios de la acción educativa.

Es indispensable para que la vida de un instituto de enseñanza media sea efectiva y fomente el desenvolvimiento de las calidades humanas que en cada uno asoman, colocar a este hombre que nace espiritualmente y empieza a ligarse a los bienes comunes de la cultura y a responder a las demandas de la convivencia social, bajo el influjo de valores morales, estéticos, científicos y filosóficos, más extensivos que profundos, pero recientes, actuales, extraídos de las corrientes culturales de nuestros días, lo que impone la exigencia de estudiar permanentemente para renovar el saber y aprovechar los efectos formativos del saber renovado, y para enlazar al hombre de la nueva generación a las ideas y al espíritu dominantes en la cultura de su tempo. (MANTOVANI, 1950, p. 129).

Taborda, como director del Colegio Nacional, impulsó la búsqueda de participación estudiantil en asuntos institucionales de todo tipo. El reconocimiento de la juventud como fuente de reflexión pedagógica se articulaba con un cuestionamiento a las formas tradicionales de autoridad en las instituciones educativas. El desarrollo de la autonomía de los estudiantes y ejercicio crítico de la participación eran en su propuesta un elemento estructurante de la pedagogía.

Esa misma preocupación era expresada por Nelson en la fundamentación del plan de reforma que acompañó: "Nuestro adolescente, a pesar de las buenas cualidades que naturalmente posee, [...] tienen del colegio nacional una visión desoladora: el colegio, para ellos, es el recinto en el cual escuchan o recitan, por obligación, cinco lecciones diarias" (Informe de la comisión de Reforma, 1934, p. 31).

La conceptualización escolanovista incluía la idea de que la conducta debía regularse exteriormente pero siguiendo las orientaciones "naturales" de la libertad humana. Lejos de la "artificiosidad normalista", proponían desplegar los sentimientos naturales. La disciplina escolar empezaba a encuadrarse más claramente en el terreno de la educación moral y política, con un objetivo central: la auto-regulación de los individuos.

Conceptos polisémicos si los hay, espontaneidad y libertad fueron términos queridos por el escolanovismo que los configuró como emblemas de lo nuevo. Desde sus posiciones específicas Nelson, Taborda y Mantovani se posicionaron en contra de la tradición de formación de una "élite ilustrada".

Aparte de su significado social e institucional, [la reforma] encierra un gran contenido pedagógico. Desde este punto de vista representa un esfuerzo para convertir la vida universitaria en actividades espontáneas, reflexivas e integrales de la juventud. [...] la reforma aspira a dar a cada joven la libertad suficiente para que en la investigación y en el estudio pueda manifestar las fuerzas originales de su mentalidad. Es decir: quiere convertirlo en un ser activo, creador de su cultura, no mero receptor de la elaborada por otros, o simple imitador de la ajena. (MANTOVANI, 1947, p. 177).

La vinculación entre los pedagogos renovadores - escolanovistas, espiritualistas, intuicionistas - y las vanguardias estéticas y políticas al inicio del movimiento, es un vínculo 
muy provechoso como analizador de las transformaciones que las instituciones iban desarrollando. Las referencias eran eclécticas: espiritualismos, idealismos, vitalismos, relativismos. Estas vertientes por la vía de la metáfora, del análisis conceptual o del diseño de respuestas a la crisis produjeron una nueva configuración pedagógica y los modos de pensar la relación de la escuela con la sociedad, una perspectiva alejada de la percepción racionalista y directivista en la que había sido pensada la tarea docente, recreándose en sus funciones, en los destinatarios para los cuáles se pensaba la enseñanza y la resolución de sus problemas en contextos sociales crecientemente complejos. No sin dificultades ni resistencias, tomaba nuevo vuelo, confrontaba con los límites de las primeras experiencias y se recreaba para dar algunos pasos hacia la diversificación del concepto de formación.

En esos años, el estado comenzó a asumir como una de sus funciones la integración de la sociedad. Así, otra faceta del corporativismo de la década de 1930 fue la de un Estado preocupado por la conformación y consolidación de cuerpos colectivos y corporaciones, como sus propios interlocutores. Los sistemas educativos adoptaron entre sus funciones centrales la formación de un fuerte nacionalismo, en sintonía con las tendencias ideológicas internacionales. En definitiva, la educación se asociaba a una nueva forma de ciudadanía, que ya no remitía al individuo liberal, sino al miembro de la corporación, del pueblo y de la sociedad nacional. Podría pensarse que es aquí donde comienza a pensarse la escuela más en función de grupo destinatario, entendido como sujeto colectivo, más que en relación a la función para la que formaban. Esto sin lugar a dudas estuvo influido por la difusión de corrientes psicológicas en las primeras décadas del siglo XX.

En las décadas del '30 y '40, las grandes corporaciones preexistentes, como la Iglesia, lograron una importante gravitación en la vida pública. Fueron momentos en los que se puso en cuestión el carácter laico, público y humanista que el sistema educativo argentino se había dado para sí mismo. Podemos hipotetizar que es el momento en el que el nivel medio pierde más decididamente su tradición de libertad de cátedra -incluso- como consecuencia de la fuerte influencia que el normalismo fue desarrollando sobre el resto de la escolarización secundaria. La táctica escolar (PUIGGRÓS, 1990) normalista fue modelando la cotidianeidad del nivel medio y las prescripciones fueron ganando terreno por sobre la autonomía de cátedra de los Colegios Nacionales. En virtud de la expansión de los esfuerzos públicos se potenció el poder de policía estatal para la escolarización de la población y se incrementó el grado de institucionalización de ésta. En 1941 se produjo una innovación que consistió en la incorporación de un ciclo básico - que había sido preanunciado en varios intentos previos de modificación - común para Bachillerato, Comercial y Normal, que pospuso la necesidad de elegir la modalidad hasta los años finales de la secundaria. Se generaba así, después de varias décadas, una modificación en el patrón original, facilitando la posibilidad de traspaso entre modalidades. Ante ello, hubo reacción por parte de los normalistas quienes temían que la mística docente de la Escuela Normal se perdiera a causa de la integración con las otras ramas. (GALLART, 1984, p. 28). Esta modificación no avanzaba sobre los contenidos y - en la conformación del tramo común - prevalecían los contenidos del Bachillerato.

En 1946 se planteó un nuevo proyecto de Ley de Educación - con postulados de justicia social y el acceso generalizado a la educación superior en el marco de peronismo que creó una nueva rama de educación técnica secundaria dirigida a los hijos de los 
trabajadores con el objeto de formar obreros calificados y técnicos medios. Esa modalidad se puso bajo la dependencia del Ministerio de Trabajo a través de la CNAOP (Comisión Nacional de Aprendizaje y Orientación Profesional). Esta dependencia del Ministerio de Trabajo en lugar del de educación puede ser leído como una modificación conceptual sobre el peso de la formación laboral por sobre la formación general. También puede pensarse como estrategia del gobierno por sortear un ámbito que le fue hostil: las instituciones educativas y su burocracia.

Esta etapa desarrolló un avance en legitimación de la educación media como derecho de los trabajadores, aunque aún de modo marginal hasta el inicio del período peronista (1946-1955). Con la llegada de éste, esa noción y su institucionalización a través de la enseñanza técnica, laboral, productiva cobró una significativa importancia. Sin embargo el fuerte impulso destinado a ella no modificó el formato tradicional del Bachillerato. Las décadas del 40 y 50 fueron decisivas para la sistematización y expansión de la educación técnica ya que además del impulso dado por el peronismo, a fines de la década del 50 incluyó la creación del Conet $^{10}$, para atender a la evolución de la estructura social y económica y considerar al trabajo como agente educativo y de capacitación. Se reorganizó así el plan de estudios buscando articular las tareas educativas al campo laboral y posibilitar salidas laborales efectivas. Esto se complementaba con cursos de formación profesional para distintos públicos (adolescentes, adultos y mujeres) y Telescuela Técnica transmitida por radio y televisión.

Por otro lado, en 1947 comienzan reformas currriculares en el nivel secundario general buscando afianzar las concepciones del gobierno peronista a través de una organización de materias y contenidos orientadas a la formación de la conciencia histórica nacional, "nuestra historia y nuestro idioma". El gobierno entendía que la experiencia educativa anterior tenía componentes extranjerizantes por lo que impulsaba la incorporación de "contenidos típicamente peronistas" (derechos laborales, función social de la propiedad, la justicia del trabajo, la nacionalización de los servicios públicos, papel preponderante de la Argentina en el plano internacional, etc. (SOMOZA RODRÍGUEZ, 2006, p. 229). Una asignatura que pasó a ocupar un lugar central fue Cultura Ciudadana, que estaba estructuraba en tres grandes apartados que correspondían, cada uno de ellos, a un curso escolar. En el primer año del Ciclo Básico del Bachillerato, Magisterio y Comercial se estudiaría la sociedad argentina; en el segundo, la economía argentina y en el tercero Formación Cívica y Organización Política. La primera parte de cada uno de ellos tenía carácter histórico, para que los alumnos, captaran los conceptos de evolución, de formación y de proceso. La última parte de cada uno de los cursos estaba dedicada a la obra del justicialismo buscando presentar la acción del gobierno peronista como el punto culminante del desarrollo argentino, "como un presente destinado a integrarse en la Historia (con mayúscula)". Como afirma Somoza Rodríguez el peronismo no hacía nada muy diferente a lo que era habitual en la enseñanza escolar de la historia argentina. El contraste, sin embargo, estaba en que el peronismo "decía que lo hacía mientras que la tradición escolar lo hacía sin decirlo". (SOMOZA RODRíGUEZ, 2006, p. 231, 233).

Hubo una nueva reforma curricular del nivel medio en 1952 con la preocupación de

${ }^{10}$ En 1959 se creó el Consejo Nacional de Educación Técnica (Conet) que integró Escuelas Industriales y Técnicas - de origen, funciones y organización distinta - en una organización común como parte del plan del presidente Frondizi para orientar la educación secundaria hacia el sector industrial. 
homogeneizar todo el ciclo básico para permitir "una formación común de la juventud argentina". Se partía de un diagnóstico de propuestas y lineamientos heterogéneos, que ofrecía a los jóvenes una serie de variantes que los "confundía". De este modo el direccionamiento se hacía cada vez más restrictivo. A posteriori de aquel ciclo básico había una división dentro del Bachillerato: por un lado, una modalidad de formación moderna y otra de formación clásica, por otro; esta última con una enseñanza intensiva del latín. (SOMOZA RODRÍGUEZ, 2006, p. 228-229). El peronismo buscó formas paralelas de instituciones de formación más que transformar sustantivamente las que preexistían. (PUIGGRÓS, 1997). Conviene agregar también que, siendo el peronismo una fuerza política que revirtió y modificó aspectos significativos de la cultura política del país, respecto de la escolaridad secundaria utilizó caminos o fórmulas ya conocidos y ensayados por gestiones anteriores: ciclo básico unificado, diferenciación en el ciclo superior, formación patriótica y moral vinculada a la ciudadanía, ampliación de la educación técnica. Tal vez la mayor innovación haya estado en la alteración de la proporcionalidad entre formación general enciclopédica y las asignaturas vinculados al mundo del trabajo. La otra gran modificación es haber ubicado como sujeto escolar preferente a los trabajadores y sus hijos. Ambos aspectos parecen haber perdido potencialidad y capacidad disruptiva a partir de los años 60s, donde las escuelas técnicas pasaron a ser recicladas (a través del Conet) en el formato tradicional que ellas habían tenido y donde la incorporación de los sectores populares no fue acompañada - salvo en algunos casos excepcionales - de políticas activas que posibilitaran el acceso, pero fundamente la permanencia y graduación de sectores sociales que no habían sido la población-objeto para la que se habría pensado la escuela media clásicamente.

Hubo que esperar hasta mediados del siglo XX para que la escuela media alcanzara características de masividad; en general, en los países occidentales la escolarización masiva de los jóvenes se dio recién avanzado el siglo XX. En esa evolución su desarrollo se irá asimilando al de las primarias, sobre todo a partir de la influencia de los profesores normalistas en las escuelas secundarias, se irán pareciendo a las escuelas primarias en el seguimiento de programas estandarizados y en la adopción de los mismos rituales (distribución de tiempos y espacios, rituales patrióticos y cotidianos, etc.) (DUSSEL, 1997), entre otras razones por la eficacia y la hegemonía desarrollada por el normalismo.

Siguiendo los estudios de Gallart podemos afirmar que la mayor expansión de la escuela secundaria se dio entre los años 1945-1950, período en el que la matrícula creció a razón de un $10 \%$ anual, y en 1950-55, lo hizo al 7,7\% porcentaje también alto en términos del crecimiento promedio. Al lustro siguiente (1955-60) corresponde la tasa menor de todo el período. En los años 60, la matrícula siguió creciendo pero a un ritmo menos acelerado. A partir de 1955, "se produjo al mismo tiempo una alta participación de la enseñanza privada, lo que también había sucedido en el período 1930-40. La proporción de la matrícula pública sobre el total de la educación secundaria era en 1920 del 86\%, disminuyó hasta el $71,9 \%$ en 1940 para alcanzar el $81,5 \%$ en 1955 , y ser en 1970 del 66,8\%. (GALLART, 1984b, p. 5).

Nos encontramos así con un panorama en el que la cobertura de la escuela media había crecido aunque también las tasas de deserción eran altísimas. Siguiendo el análisis estadístico de Giuliodori y otros, la tasa de acceso muestra una tendencia creciente a lo largo del periodo 1950-1992. Si se relacionan las tasas de acceso y deserción se tiene que, 
en los últimos años de la década del 80', aproximadamente dos tercios de la población que estaba en condiciones de acceder a estudios de nivel medio los iniciaba, pero poco más del $40 \%$ de esas personas los concluía, mientras que en la década del 50' ingresaba un $40 \%$ y se graduaba alrededor del $60 \%$. Los autores también destacan que se puede observar un comportamiento curioso de la tasa de deserción, ya que en los primeros quinquenios del periodo analizado (1950-55 hasta 1961-65) disminuye en forma sostenida desde algo menos del 50\% hasta cerca del 30\%, y luego inicia una tendencia ascendente para llegar, a principios de los años noventa, a superar el nivel que exhibía al comienzo de los cincuenta. (GIULIODORI et al., 2004).

\section{La segunda mitad del siglo $\mathrm{XX}$}

El sistema de educación secundaria que había sido concebido desde mediados del siglo XIX, alcanzó una gran expansión al promediar el siglo XX. Los análisis, diagnóstico y propuestas de solución se reorganizaron en torno a una serie de nociones estructurales: la cobertura, la deserción, el desgranamiento, la sobredad. A partir deesos años, se produce una sociologización del discurso de las políticas educativas y la reflexión pedagógica quedó en un segundo plano. Esto que ocurrió en relación a las políticas para el nivel secundario, tuvo su correlato en la transformación que se operó en las carreras de Ciencias de la Educación y en las políticas educativas, una creciente sociologización del campo y la pedagogía pasó a ocupar un segundo plano.

Los años 60s mostraron el apogeo de los organismos técnico-pedagógicos, con un creciente peso en la definición de políticas, así como la difusión y adopción de la planificación - como una nueva tecnología de intervención social promovida y difundida por organismos internacionales como la OCDE, el Banco Mundial y la Unesco. Una de las grandes innovaciones de esos '60 fue la instalación de la técnica y la tecnología en el marco de la escuela. Ese escenario, mostraba la declinación del educador humanista, propia de la matriz generalista que sumaba y consolidaba las experiencias normalista y espiritualista y la aparición del "especialista en educación"que basaba su legitimidad en el conocimiento empirico sistematico y en la expertez técnica. ${ }^{11}$ La denominación de práctico idóneo afianzó la diferenciación entre trabajo manual e intelectual, como una instancia "a mitad de camino" entre ambas modalidades con algunos rasgos de trabajo intelectual pero mucho de artesanal.

Así, nociones como desarrollismo, medios masivos de comunicación y tecnología educativa comenzaron a plantearse como nuevas demandas hacia la educación. Siguiendo a Hobsbawm (1998) diremos que los procesos de modernización de la estructura burocrática del Estado que se impulsaron a lo largo de la década constituyeron la expresión local de las tendencia mundiales de expansión del Estado planificador de postguerra. Asimismo, comienza un proceso en el que el sistema educativo empieza a mostrar fuertes signos de crisis, que vino acompañada de análisis críticos o declaración de insuficiencia del

\footnotetext{
11 Aunque ya hemos citado en otros trabajos que podría argumentarse que ya estaba implícita en algunos movimientos anteriores, cómo el tecnicismo de la escuela nueva y el cientificismo y la confianza casi ciega en el avance tecnológico de los positivistas normalizadores, hay que destacar que la invasión de la pedagogía por objetivos, la planificación, la voluntad taxonómica y clasificatoria fueron profundizaciones y radicalizaciones de lo anterior que dejaron huellas propias en nuestras aulas, consonante con el modelo desarrollista.
} 
sistema educativo consolidado hasta ese momento.

La segunda mitad del siglo $X X$ es el momento en que el nivel medio ve incrementado su cantidad de instituciones y alumnos matriculados. Sin embargo, otro fenómeno va a acompañar - fundamentalmente a partir de 1960 - esa cobertura: la deserción o la expulsión de quienes no transitaran exitosamente ese modelo escolar. No es que se tratara de un fenómeno nuevo ya que la deserción existió desde el comienzo mismo del modelo. Para el período 1886-1891 el porcentaje de desgranamiento en los colegios nacionales fue del 68\% (TEDESCO, 1986); pero en el siglo XIX y comienzos del $X X$ - orientado por percepciones disciplinarias y elitistas - la deserción no constituía una preocupación como sí va a serlo en la segunda mitad del siglo XX, lo que da cuenta de la existencia de otra función social asignada a la escuela. Son las políticas estatales - por ejemplo la medición y el seguimiento estadístico - las que problematizan y transforman las trayectorias desiguales "en algo acerca de lo que era posible estar preocupado". (HUNTER, 1998, p. 138).

La preocupación por la educación fue central en el modelo desarrollista hegemónico, que veía el problema de seguridad que la pobreza representaba. Cobraron importancia diversas propuestas como la de "educación permanente", "extensionismo agrícola", "formación de líderes", y otras que, sostenidas por la teoría del capital humano reconocían la importancia de educación en beneficio del desarrollo capitalista.

Las décadas del 60 y el 70 van a marcar, así, una serie de nuevas expresiones: la comprensión del desarrollismo pedagógico, a veces entendido como un epifenómeno de la economía, al que se accedía a través de la planificación. Fueron quedando en un segundo plano, aquellos que buscaban desarrollar el espíritu del educando o del sujeto pueblo, y cuya vinculación con el desarrollismo se había dado a través de experiencias transformadoras influidas por la obra de Paulo Freire y la teorización desescolarista. Dicho de otro modo, quienes se apropiaban de las prescripciones (fundamentalmente externas) para alcanzar el modelo de desarrollo por un lado; $y$, por otro, quienes planteaban el análisis a través de la categoría dependencia, y se preocupaban por la inclusión de los distintos sectores sociales y la superación del modelo societal. La primera de esas tendencias, hegemonizó el terreno de las políticas educacionales mientras la segunda fue quedando en los márgenes, vinculada a experiencias informales y de menor alcance.

Quisiéramos señalar dos aspectos, como notas centrales de la tendencias de esa nueva etapa: por un lado, se afianzaba una diferenciación del campo educativo y de la producción de conocimientos, inclusive el conocimiento sobre educación. Por otro, la Pedagogía -como cuerpo de saberes educativos, va pasando de la tendencia de corte filosófico-especulativo- que había afianzado durante el auge del espiritualismo, hacia una mirada más centrada en la experimentación, la secuenciación, observación y medicion de los procesos educacionales que vinculaba a la enseñanza con una serie de aprendizajes instrumentales.

\section{Algunas notas para concluir o sobre el eterno retorno}

Este recorrido nos ha posibilitado mostrar la conformación hegemónica del formato escolar: el saber escolar organizado en ramos, su enseñanza simultánea, el curriculum graduado, una secuencia fija, el ciclo escolar, el enfoque generalista y enciclopédico, el agrupamiento en base a la edad, el aula/sección como unidad espacial, la distribución de 
tiempos y espacios, los rituales patrióticos. También llegamos a la conclusión de la gran recurrencia de las propuestas de solución y mejoramiento ofrecidas durante décadas: ciclo básico/ciclo superior; ciclo general/ciclo preparatorio; ciclo básico/ciclo de especialización o ciclo único fueron opciones que reaparecieron en numerosas ocasiones a lo largo de la historia. Más allá de su recurrencia, esas alternativas transformaron poco el curriculum y el formato. Las propuestas - de distinto signo e intención - que avanzaron en modificar el formato - o algunos de sus rasgos - fueron vueltas atrás o debilitadas en sus pretensiones transformadoras, absorbidas en las gramáticas institucionales y en las construcciones sociales sobre lo legítimo, lo prestigioso o aquello considerado de calidad. La forma o formato escolar no se confunde estrictamente con la institución escolar, ni es limitada por ella, ya que es transversal a diversas instituciones y grupos sociales. (VINCENT; LAHIRE; THIN, 1994).

Comenzamos este artículo hablando de los mitos fundantes. El filósofo rumano Mircea Eliade desarrolla la noción del mito del eterno retorno para analizar el rechazo de la idea del progreso como rebeldía frente al tiempo concreto y por una nostalgia que favorece un regreso periódico a los mitos de los orígenes. El autor destaca en ello una negación de la historia por parte de las sociedades primitivas que se expresa por medio de los arquetipos y la repetición, los modos de insertarlo en un relato - podríamos emparentarlo con la noción de gramática que hemos usado - para aliviar el carácter extraño de la experiencia (ELIADE, 1991). El reconocimiento de lo inesperado, la duda, la dislocación provocan reacciones antiprogreso que busca generar certezas que logren detener el continuo cuestionamiento, articular representaciones del mundo con validez universal.

Como hemos intentado mostrar, las escuelas secundarias fueron el producto del cruce de múltiples tendencias frente al desafío de la masificación; en ello se destaca la experiencia de la continuidad del modelo institucional de las escuelas enciclopedistas de elite, frente a la tendencia de ruptura que supusieron las nuevas modalidades producidas en el momento de expansión de la escuela secundaria. Como hemos visto, esa ruptura fue absorbida por la gramática en numerosas ocasiones. Esta forma de configuración de las instituciones de nivel medio funcionó como un modelo, una imagen para la escolarización de los jóvenes, que muchas veces constituyó un límite a la inclusión de lo nuevo. Por otro lado, ese modelo incluyó una perspectiva de futuro orientada a la inclusión en la administración de los lugares dirigenciales, para dialogar con cierta jerarquía de saberes academicistas donde algunas experiencias sociales quedaban fuera (como el trabajo, los oficios o la técnica), para cumplir roles sociales ya previstos y escasos y dejando de lado otras experiencias vitales mientras se era alumno.

No deberíamos quedarnos con la simple afirmación de que "nada ha cambiado" ni - menos aún - que no pueda cambiarse. Vincent, Lahire y Thin remarcan que la forma escolar se construyó y se construye en las luchas y transformaciones. Lo que sí quisiéramos remarcar es que el hecho de no incluir una perspectiva histórica del devenir de nuestras instituciones torna difícil la comprensión de las invariantes de la forma escolar, así como las luchas y los conflictos a través de los cuales ella se construye y perdura. También podemos afirmar que algunos aspectos se han modificado. Además de la actualización de contenidos dentro de las disciplinas, nuestras escuelas ya no parecen responder a las descripciones de esas instituciones rígidas, casi carcelarias, definidas por el encierro y la férrea disciplina. Hemos hecho referencia a elementos que sí han resultado modificados, como la limitación 
de la libertad de cátedra o la rígida separación entre el afuera y el adentro de la escuela la vida mundana y la vida escolar -.

La equivalencia que se construyó entre enseñanza general y curriculum enciclopédico humanístico (DUSSEL, 1997) se consolidó como posición hegemónica que en distintas momentos y revisiones producidas durante todo el siglo XX emergió actualizado y renovado. Ese modo de construcción del curriculum se consolidó como un patrón cultural que logró articular las expectativas y estrategias político-culturales de diversos grupos, y así, convertirse en el sentido común mismo. Esa prevalencia del Bachillerato enciclopédico y humanista como el sinónimo de la idea misma de escuela secundaria, funcionó como el telón de fondo contra el que se confronta cualquier otro modelo escolar que plantee alguna diferencia. En este sentido, ante el desafío actual de la universalización de la escuela media - una meta deseable hacia la cual se han efectuado avances - cabe interrogarse acerca de qué es lo que se quiere universalizar, si se trata de la "biblioteca de asuntos inconexos" en la que no se puede intercambiar de estante, como nos relataba Nelson o una escuela que habilite trayectorias autónomas, en la que los alumnos sean considerados dignos de acceder y apropiarse del patrimonio que les corresponde por derecho, independientemente del sector social en el que hayan nacido.

\section{Referencias}

BENTIVENGA, Diego. El poder de la letra. Literatura y domesticación en la Argentina. La Plata, UNIPE: Editorial Universitaria, 2011.

DUSSEL, Inés. Currículum, humanismo y democracia en la enseñanza media (18631920). Buenos Aires: Flacso/UBA, 1997.

ELIADE, Mircea. The myth of the eternal return. Or Cosmos and History. Princeton: Princeton University Press, 1991.

FUNES, Patricia. Salvar la Nación. Intelectuales, cultura y política en los años veinte latinoamericanos. Buenos Aires: Prometeo, 2006.

GALLART, Ma. Antonia. La construcción social de la escuela media. Una aproximación institucional. Buenos Aires: Editorial Stella/La Crujía, 2006.

La evolución de la educación secundaria 1916-1970: Expansión e inmovilidad. (I)

Los cambios cualitativos. Revista C.I.A.S., XXXIII, 330, p. 22-37, marzo de 1984a.

La evolución de la educación secundaria 1916-1970: (II) El crecimientocuantitativo de la matrícula y su impacto en la fuerza de trabajo". Revista C.I.A.S., XXXIII, 331, p. 420, 1984b.

GIULIODORI, Roberto F.; GIULIODORI, María Andrea; GONZÁLEZ, Mariana. La deserción en el nivel medio de la educación en la República Argentina. Cálculo de tasas de abandono e identificación de algunos factores que se le asocian. Revista de Economía y Estadística, Universidad Nacional de Córdoba, v. XLII, 2004.

HUNTER, Ian. Repensar la escuela: subjetividad, burocracia y crítica. Barcelona: Pomares, 1998.

MANTOVANI, Juan. Ciencia y conciencia de la educación. Problemas, esquemas y experiencias. Buenos Aires, El Ateneo, 1947.

La enseñanza técnica industrial. Buenos Aires: Ministerio de Justicia e Instrucción Pública, 1937.

Proyecto de reformas a los planes de estudio de la enseñanza media. Buenos Aires: Ministerio de Justicia e Instrucción Pública, 1934. 
PUIGGRÓS, Adriana. Dictaduras y utopías en la historia reciente de la educación argentina (1955-1983). Tomo VIII de Historia de la Educación Argentina. Buenos Aires: Galerna, 1997.

Sujetos, disciplina y currículo en los orígenes del sistema educativo argentino (1885-1916). Tomo I de Historia de la Educación Argentina. Buenos Aires: Galerna, 1990.

SOUTHWELL, Myriam. El formato escolar en cuestión: reflexiones sobre pasado, presente y futuro. In: PINI, Mónica et al. (Coords.). La educación secundaria, ¿Modelo en (re) construcción? Buenos Aires: Aique, 2012. p. 91-112.

. Escuela media y formación para el mundo político. Diálogos entre generaciones y tradiciones. In: Espacios en Blanco. Serie Indagaciones. Tandil: UNCPBA, n. 19, 2009. p. 30-40.

La educación secundaria en Argentina. Notas sobre la historia de un formato. In: TIRAMONTI, Guillermina (Coord.). Variaciones sobre la forma escolar. Desafíos a la escuela media tradicional en un contexto fragmentado. Rosario: Homo Sapiens, 2011. TABORDA, Saúl. Investigaciones pedagógicas. v. 2. Córdoba: Ateneo Filosófico de Córdoba, 1951.

La Crisis Espiritual y el Ideario Argentino. Conferencia pronunciada bajo los auspicios del Instituto Social. Santa Fe: Instituto Social de la Universidad Nacional del Litoral, 1933.

TEDESCO, Juan C. Educación y Sociedad en la Argentina (1880-1945). Buenos Aires: Ediciones del Solar, 1986.

TYACK, David; CUBAN, Larry. En busca de la Utopía. Un siglo de reformas en las escuelas públicas. México: Fondo de Cultura Económica, 2000.

VINCENT, Guy; LAHIRE, Bernard; THIN, Daniel. Sur l'histoire e la théorie de la forme scolaire. In: VINCENT, Guy (Dir.). L'éducation prisionnière de la forme scolaire? Scolarisation et socialisation dans les sociétés indsutrielles. Lyon: Presses Universitaires de Lyon, 1994.

MYRIAM SOUTHWELL es investigadora independiente Conicet/Universidad Nacional de La Plata, directora del Doctorado en Ciencias de la Educación de la Universidad Nacional de La Plata. Fue presidente de la Sociedad Argentina de Historia de la Educación entre 2008 y 2012 y desde 2016 es integrante del Comité Ejecutivo de International Standard Conference on History of Education (Ische). Autora de numerosos trabajos en temas de historia y política de la educación entre los cuales se destacan Ideas en la Educación Latinoamericana. Un balance historiográfico (junto con Nicolás Arata), Unipe, 2014; Reflexiones sobre el Congreso Pedagógico Internacional de 1882 (junto con Jorge Bralich), Trilce, 2014; Schooling and Governance: Pedagogical Knowledge and Bureaucratic Expertise in the Genesis of the Argentine Educational System, Paedagogica Historica, v. XLIX, 2013; La educación y lo justo. Ensayos acerca de las medidas de lo posible, Unipe, 2013; Entre Generaciones. Exploraciones sobre educación, cultura e instituciones, Homo Sapiens, 2012.

Dirección postal: Calle 135, nro. 145, 1896, La Plata, Argentina.

E-mail: islaesmeralda@gmail.com

Recebido em 17 de abril de 2018.

Aceito em 25 de junho de 2018. 